\title{
PEMBUATAN BAHAN BAKAR EMULSI MENGGUNAKAN ETANOL AREN DALAM UPAYA MENURUNKAN EMISI $\mathrm{CO}_{2}$
}

\author{
Novena Rawung ${ }^{1)}$, Hanny Frans Sangian ${ }^{1)}$, Gerald Hendrik Tamuntuan ${ }^{1)}$ \\ ${ }^{1)}$ Program Studi Fisika FMIPA UNSRAT Manado, 95115
}

\begin{abstract}
Research has been conducted to tackle the problem of $\mathrm{CO} 2$ emissions. Ethanol is a material that is often used, because it is a renewable energy obtained from the sugar fermentation process. Ethanol used for mixing is that which has been through the process of reflux fermentation and distillation. The first stage is the manufacture of ethanol by using a distillation process to obtain purity above $80 \%$. The next stage is the mixing process carried out with a concentration of ethanol with a purity of $92 \%-98 \%$, and the results of cracking kerosene with several variations of the boiling point. Kerosene was poured into a measuring cup with a volume of $7 \mathrm{ml}$ and ethanol $92 \%-98 \%$ concentration was slowly added to form an emulsion. The results show that a mixture of kerosene, water and ethanol purity of 98\%, only a small volume is needed to become 1 phase. But, for mixing kerosene, water and 92\% ethanol purity, it takes a lot of volume. The easily mixed result is that the first kerosene product is 192-198 ${ }^{\circ}$ Cbecause it approaches the carbon gasoline chain. Meanwhile, for the results of kerosene products $272-276{ }^{\circ} \mathrm{C}$ is rather difficult to be mixed into 1 phase because, the carbon chain approaches diesel fuel.
\end{abstract}

Keywords: Ethanol, Kerosene, Emulsion, Palm Tree (Arenga pinnata)

\begin{abstract}
ABSTRAK
Telah dilakukan penelitian untuk menanggulangi masalah emisi CO2. Etanol menjadi bahan yang sering digunakan, karena merupakan energi terbarukan yang diperoleh dari proses fermentasi gula. Etanol yang digunakan untuk pencampuran yaitu yang telah melalui proses fermentasi dan destilasi refluks. Tahapan yang pertama yaitu pembuatan etanol dengan menggunakan proses destilasi untuk mendapat kemurnian diatas $80 \%$. Tahapan selanjutnya yaitu proses pencampuran dilakukan dengan konsentrasi etanol dengan kemurnian 92\%-98\%, dan hasil cracking kerosene dengan beberapa variasi titik didih. Kerosene dituangkan kedalam gelas ukur dengan volume $7 \mathrm{ml}$ dan etanol konsentrasi 92\%-98\% dimasukkan secara perlahan hingga membentuk emulsi. Hasilnya menunjukkan bahwa campuran antara kerosene, air dan kemurnian etanol 98\%, hanya dibutuhkan sedikit volume untuk menjadi 1 fasa. Tapi, untuk pencampuran kerosene, air dan kemurnian etanol 92\% dibutuhkan volume yang banyak. Hasil yang mudah tercampur yaitu produk kerosene yang pertama $192-198^{\circ} \mathrm{C}$ karena, mendekati rantai karbon gasoline. Sedangkan, untuk hasil produk kerosene $272-276^{\circ} \mathrm{C}$ agak sulit tercampur menjadi 1 fasa karena, rantai karbonnya mendekati bahan bakar diesel.
\end{abstract}

Kata kunci : Etanol, Kerosene, Emulsi, Pohon Aren (Arenga pinnata) 


\section{PENDAHULUAN}

Permasalahan utama yang sering terjadi di seluruh dunia, adalah berkurang produksi bahan bakar minyak bumi karena tidak dapat mengimbangi penggunaan bahan bakar minyak. Cadangan minyak bumi serta produksi di Indonesia mengalami penurunan sampai $10 \%$ setiap tahunnya (Bambang, 2006). Sebesar 73\% produksi gas karbon dioksida adalah hasil dari pembakaran bahan bakar minyak (Wildenborg dan Lokhorst, 2005). Penggunaan bahan bakar perlu dibatasi untuk mengurangi kadar polutan hasil produksi CO2 (Demirbas, 2006).

Penggunaan bahan bakar yang berlebihan dapat menyebabkan sumber produksi bahan bakar semakin menipis. Karena hal itu, pemerintah berpikir keras untuk menanggulangi masalah ini dengan pengembangan bahan bakar berbasis ramah lingkungan yang dilakukan para peneliti untuk membantu masalah produksi bahan bakar semakin berkurang.

Saat ini ahli sedang giat-giatnya mengembangkan bahan-bahan dari sumber terbarukan (renewable resources) menjadi material yang bernilai ekonomis (Widjaya dkk, 2015; Sangian dkk, 2019; Sangian dkk, 2018; Sangian dkk, 2015)

Khalil dan Gupta, (2012) meneliti bahwa karakteristik dari pembakaran terdistribusi menggunakan bahan bakar campuran yang komponennya yaitu metana dan propana cair. Peneliti (Garai dkk, 2017) melakukan eksperimen tentang penambahan etanol dalam kerosene yang mengarah karakteristik semprotan kerosene murni dan $10 \%$ etanol. Etanol yang dicampur dengan minyak tanah menggunakan alat penyemprot hibrid pada turbin gas. Investigator (Patra dkk., 2015) melakukan studi tentang karakteristik dan juga kinerja pembakaran di dalam ruang bakar saat dioperasikan dengan kerosene dan juga campuran kerosene-etanol. Bahan yang digunakan yaitu kerosene, dan campuran etanol dengan komposisi $5 \%$ dan $10 \%$.

Riset telah dilakukan yang berhubungan dengan penelitian ini tapi menggunakan substansi yang berbeda. Peneliti (Najafi dkk., 2015) telah melakukan eksperimen dengan menggunakan etanol dan gasoline yang mana komposisi etanol adalah 5\%, $7,5 \%, 10 \%, 12,5 \%$ dan $15 \%$ yang bisa disebut dengan E5, E7,5, E10, E12,5 , dan E15. Eksperimen sebelumnya dilakukan dengan mencampur biodiesel, diesel dan etanol. Komposisi etanol bervariasi pada $3 \%, 5 \%, 15 \%$, dan $25 \%$ dalam campuran biodiesel, diesel, dan etanol yang biasa disebut dengan BDE3, BDE5, BDE15, dan BDE25 (Yilmaz dkk., 2013). 
Investigator (Sangian dkk., 2017) telah melakukan penelitian tentang pemanfaatan etanol yang dicampur dengan bensin jenis premium (RON 88) sehingga menjadi satu fasa. Penemuan ini diperoleh bahwa pada komposisi tertentu antara etanol, bensin dan air akan membentuk larutan homogen.

Peneliti (Patil dan Thipse, 2015) telah melakukan eksperimen untuk mengevaluasi efek dari oksigenated cetane improver diethyl ether yang dicampur dengan kerosene dan diesel pada pembakaran. Komposisi minyak tanah $5 \%, 10 \%$ dan $15 \%$ dicampur dengan solar dan kemudian diselidiki efek dari pencampuran pada pembakaran. Tes mesin dilakukan pada $10 \%, 25 \%, 50 \%$, $75 \%$ dan $100 \%$ dari beban penuh untuk semua uji bahan bakar. Hasil uji bahan bakar di laboratorium menunjukkan bahwa diethyl ether (DEE) dapat dicampur dengan diesel dan kerosene dalam proporsi apapun. Peneliti (Rakopoulos dkk., 2010) telah melakukan percobaan untuk mengevaluasi efek penggunaan campuran butanol normal dengan bahan bakar diesel konvensional, dengan komposisi butanol 8\%, 16\%, dan 24\%. Pengujian dilakukan dengan menggunakan masing-masing bahan bakar campuran atau bahan bakar diesel dengan menggunakan mesin yang bekerja pada kecepatan 2000rpm dan pada tiga beban yang berbeda.

Hingga saat ini pembuatan bahan bakar emulsi antara etanol ditambah bensin, etanol ditambah kerosene, dan etanol ditambah diesel masih menggunakan etanol murni yang mana konsentrasinya yaitu minimal $99,5 \%$ atau yang disebut unhydrous ethanol. Untuk pembuatan etanol absolut sangat sulit, sehingga harganya masih mahal. Etanol berair (aqueous ethanol) yang paling memungkinkan untuk dapat dicampur dengan bahan bakar fosil, tapi dengan komposisi yang sesuai.

Penelitian ini diarahkan untuk membuat bahan bakar emulsi dengan beberapa campuran antara air, kerosene dan etanol dalam larutan homogen satu fasa. Air nira pohon aren sebagai bahan baku etanol telah dilakukan fermentasi kemudian diolah dan dimurnikan menggunakan proses destilasi refluks untuk mendapat kadar yang lebih tinggi. Konsentrasi etanol yang akan dicampur dengan kerosene untuk menjadi bahan bakar emulsi divariasikan mulai dari etanol 92\% sampai 98\%. Adapun prosedur yang dilakukan yaitu dimulai dengan meng-cracking kerosene dan mendapatkan hasil dengan beberapa titik 
didih tertentu. Kemudian, hasil dari cracking dicampur dengan beberapa variasi komposisi etanol sehingga menjadi satu fasa

\section{METODOLOGI PENELITIAN}

\section{Alat dan Bahan}

Bahan yang digunakan Etanol (Terfermentasi dari nira aren), dan kerosene. Alat yang digunakan yaitu, boiler (volume $12 \mathrm{~L}$ ), kolom (panjang $200 \mathrm{~cm}$ dan diameter $15,24 \mathrm{~cm}$ ), kondensor (panjang $200 \mathrm{~cm}$ ), termometer digital dari LH 666198 dengan termokopel NiCr-Ni $\left(-50\right.$ sampai $\left.+1200^{\circ} \mathrm{C}\right)$, air circulator elektronik, pompa air, dan power supply

\section{Prosedur pembuatan etanol $96 \%$ pada proses destilasi}

Pembuatan etanol $96 \%$ diproses oleh alat destilasi refluks. Hasil fermentasi dari nira aren dimasukkan ke dalam boiler dan dipanaskan untuk memisahkan air dari bioetanol dengan suhu dalam boiler dikontrol termometer. Pada proses pemanasan, uap yang dihasilkan naik ke kolom dan mengembun, nantinya menetes ke bawah. Proses akan terus dilakukan sampai bioetanol mencapai kemurnian 95\% sampai $96 \%$. Pada proses pemisahan, dilakukan pengontrolan jumlah refluks uap pada kolom. Uap yang naik pada atas kolom dihubungkan dengan kondensor untuk mengubah kembali uap menjadi cairan. Cairan ini merupakan hasil dari proses destilasi refluks bioetanol, yang nantinya digunakan pada proses pembuatan emulsi.

\section{Prosedur Cracking Kerosene}

Proses cracking kerosene menggunakan kompor dan alat untuk cracking. Kerosene dipanaskan dalam tungku. Uap yang dihasilkan akan naik dan melewati proses pendingingan pada kondensor, dengan perkiraan suhu titik didih kerosene sebesar $150^{\circ} \mathrm{C}-275^{\circ} \mathrm{C}$. Cairan yang telah didinginkan pada kondensor adalah hasil proses cracking dari kerosen dengan variasi titik didih tertentu.

\section{Prosedur pembuatan emulsi}

Dalam proses pembuatan emulsi akan dilakukan secara manual yaitu dengan mencampurkan secara langsung etanol dengan kerosene.

Sebelum pencampuran, konsentrasi etanol hasil destilasi diukur dengan alkoholmeter. Kerosene yang digunakan sebanyak $7 \mathrm{ml}$ dimasukkan ke dalam gelas ukur untuk diproses menjadi satu fasa. Etanol dengan kadar/konsentrasi tertentu dimasukan dengan perlahan ke dalam gelas ukur yang berisi kerosene hasil cracking dan dicampur sampai memperoleh satu fasa. Etanol dengan 
konsentrasi tersebut dicampurkan untuk 12 variasi titik didih hasil cracking kerosene. Proses pencampuran ini dilakukan dari kemurnian etanol 92\% sampai $98 \%$ hingga menjadi satu fasa.

\section{HASIL DAN PEMBAHASAN}

\section{Pemisahan Etanol Dengan Air Dengan Menggunakan Destilasi Refluks}

Penelitian dimulai pada pukul

08.00 WITA dengan proses awal yaitu pemanasan tuak aren dengan suhu awal yang terbaca yaitu $35^{\circ} \mathrm{C}$. Setelah 125 menit sejak proses separasi, suhu naik menjadi $79^{\circ} \mathrm{C}$ dan etanol mulai menetes. Hasil etanol yang menetes dalam gelas ukur sebanyak $100 \mathrm{ml}$ dan kemudian dilakukan pengukuran menggunakan alkoholmeter untuk melihat tingkat kemurniannya yang mencapai $87,5 \%$. Setelah selang 10 menit, suhu naik menjadi $81^{\circ} \mathrm{C}$ serta volume etanol yang terdapat pada gelas ukur hingga 100ml, kemudian didapatkan kemurniannya $85 \%$. Setelah selang beberapa menit, dilakukan pengawasan pada suplai panas sehingga suhu yang terbaca menjadi $79,5^{\circ} \mathrm{C}, 79,3^{\circ} \mathrm{C}$ dan $79,6^{\circ} \mathrm{C}$ hasil yang didapat untuk kemurnian etanol bervariasi dari $89 \%$, 90\%, hingga $91 \%$. Berikutnya, suhu turun hingga $78^{\circ} \mathrm{C}$ dan mendapatkan kemurniaan $93 \%$ sampai mencapai 96\%. Setelah itu suhu meningkat menjadi $82^{\circ} \mathrm{C}$ dan kemurnian yang didapat menjadi $63 \%, 43 \%$, dan $38 \%$. Hal ini diakibatkan karena volume etanol dalam tuak aren telah habis sehingga konsentrasi etanol menurun.

Suhu panas rendah sekitar $78-79^{\circ} \mathrm{C}$ dapat menghasilkan kadar kemurnian etanol yang tinggi hinga mencapai $96 \%$ dan jika suhu panas tinggi kadar kemurnian etanol akan menurun menjadi $63 \%$, 43\%, dan 38\%. Hal ini disebabkan karena volume etanol dalam tuak aren habis, sehingga mencapai titik didih air.

\section{Proses Cracking Kerosene}

Dalam proses cracking kerosene, awalnya kerosene dimasukkan ke dalam tungku (boiler) untuk dipanaskan. Volume kerosene yang dimasukkan kedalam tungku sebanyak 1,5 liter dan suhu awal yaitu $50^{\circ} \mathrm{C}$. Setelah selang waktu 41 menit, suhu naik menjadi $192^{\circ} \mathrm{C}$ dan kerosene mulai menetes perlahan-lahan. Hal ini terjadi disebabkan uap panas dari kerosene naik ke kolom destilasi dan kemudian melalui proses pendinginan, sehingga keluar menjadi cairan produk baru (cracked kerosene). Selanjutnya dalam waktu 10 menit, suhu naik menjadi $198^{\circ} \mathrm{C}$. Untuk mendapatkan hasil kedua dibutuhkan waktu selama 2 menit dengan suhu $202^{\circ} \mathrm{C}$ sampai $204^{\circ} \mathrm{C}$ dengan volume 118ml. Dengan proses yang sama, 
diperoleh produk yang baru dengan suhu berbeda tapi waktu yang sama.

Proses Cracking Kerosene ini, dilakukan juga di Laboratorium Teknik Kimia ITB untuk melihat perbandingan. Setelah melakukan proses cracking kerosene di ITB, ada perbedaan sedikit pada hasil perbandingan suhunya. Hal ini disebabkan karena perbedaan suhu ruang di Manado dan di Bandung berbeda, dan juga alat yang digunakan. Sehingga proses cracking mulai menetes pada suhu $183^{\circ} \mathrm{C}$ $196^{\circ} \mathrm{C}$. Kemudian, proses selanjutnya berlangsung sama, dan hanya membutuhkan waktu sekitar 2 menit - 3 menit untuk mendapatkan 1 botol dengan konsentrasi suhu yang berbeda.

Untuk produk kerosene yang pertama (192-198) volume yang didapat tidak terlalu banyak karena, cairan akhir yang menetes sangat pelan sehingga membutuhkan waktu 10 menit untuk mendapatkan volume $68 \mathrm{ml}$. Untuk produk kerosene selanjutnya jumlah volume yang dihasilkan perlahan naik karena, cairan akhir yang menetes sangat cepat sehingga 3 menit saja sudah mendapatkan $118 \mathrm{ml}$. Hal ini dikarenakan semakin tinggi suhu, cairan yang menetes semakin cepat hingga batas titik didih dari kerosene, cairan yang menetes akan perlahan menurun. Proses cracking kerosene ini dilakukan dengan tujuan untuk pemutusan rantai karbon, agar lebih pendek dan mudah tercampur dengan etanol-air.

\section{Pencampuran (blending) Etanol dengan hasil Cracking Kerosene}

Kerosene dimasukkan ke dalam gelas ukur sebanyak $7 \mathrm{ml}$ dan kemudian dicampur dengan etanol $92 \%$ secara perlahan hingga mencapai satu fasa. Untuk proses ini dilakukan sebanyak 12 kali dikarenakan hasil cracking kerosene yang diperoleh sebanyak 12 produk dengan suhu yang berbeda. Pencampuran hasil cracking kerosene dan etanol dimulai dengan suhu yang terendah yaitu $192^{\circ} \mathrm{C}-198^{\circ} \mathrm{C}$ hingga suhu yang tertinggi yaitu $272^{\circ} \mathrm{C}-276^{\circ} \mathrm{C}$.

Volume produk satu fasa yang didapat untuk setiap pencampuran adalah berbeda. Ini disebabkan bahwa struktur dan sifat produk, seperti kerapatan, titik didih, dan tekanan uap dari kerosene yang dihasilkan dipengaruhi oleh suhu cracking. Sifat ini berpengaruh besar pada seberapa kuat produk kerosene membentuk satu fasa dengan etanol pada kemurnian berbeda-beda. Telah ditemukan bahwa semakin rendah konsentrasi etanol yang dicampur, semakin banyak etanol yang diperlukan. Tetapi, semakin tinggi konsentrasi etanol 
yang dicampur, semakin sedikit etanol yang diperlukan.

Untuk suhu yang paling rendah hanya perlu volume etanol yang tidak terlalu banyak. Dari hasil pencampuran, suhu terendah paling mudah tercampur dengan etanol karena rantai karbon yang dimiliki hampir mendekati bensin, dimana sangat mudah tercampur dengan etanol. Sedangkan untuk suhu paling tinggi, membutuhkan volume etanol yang banyak karena agak susah untuk bercampur menjadi satu fasa. Hal ini dikarenakan rantai karbon dari suhu paling tinggi, sudah mendekati solar dimana agak sulit untuk tercampur dengan etanol. Dari hasil penelitian yang telah diambil, dapat diketahui untuk kemurnian etanol paling rendah yaitu $92 \%$ membutuhkan lebih banyak etanol dibandingkan dengan kemurnian yang paling tinggi yaitu $98 \%$.

Untuk pencampuran etanol dan kerosene juga dilakukan di laboratorium teknik Kimia ITB untuk melihat perbandingan. Dari hasil yang telah dilakukan di sana, terdapat hasil yang sedikit berbeda dikarenakan perbedaan suhu ruang, dan penggunaan alat.

\section{Deskripsi Tegangan Permukaan}

Dalam melakukan proses pencampuran, etanol berperan sebagai surfaktan dan juga zat pelarut, termasuk juga dengan kerosene. Etanol dan kerosene dapat tercampur menjadi satu fasa karena adanya proses yang terjadi yaitu surfaktan, dimana di dalam surfaktan terdapat gugus hidrolik dan lipofilik. Gugus hidrolik yang dimiliki pada surfaktan memiliki sifat polar karena dapat bersenyawa dengan air, dan gugus lipofilik memiliki sifat non polar yang dapat bersenyawa dengan minyak. Hal ini menyebabkan surfaktan merupakan bahan yang berperan penting. Dimana jika volume etanol dinaikkan maka tegangan permukaan larutan menjadi konstan.

Hal lain yang dapat mempengaruhi proses pencampuran etanol, air, dan kerosene menjadi satu fasa yaitu interaksi listrik yang dimiliki gugus atom pada masing-masing molekul seperti yang ditunjukkan pada gambar 1 .

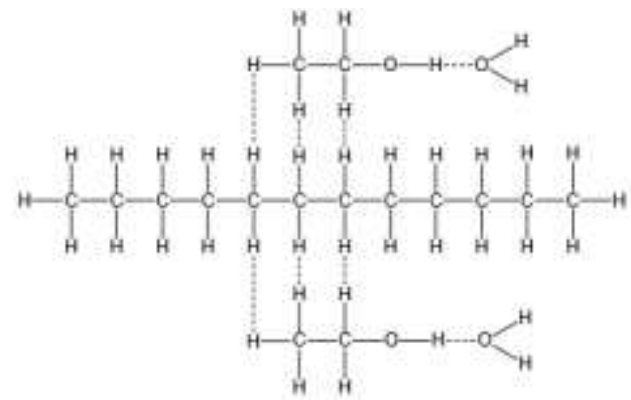

Gambar 1. Diagram ikatan antara etanolair (polar) dan kerosene-etanol (non-polar) sebagai surfaktan 


\section{Hubungan Etanol-Air-Kerosene}

Dari data hasil pencampuran antara kerosene, air dan etanol menjadi satu fasa, dapat dilihat dengan menggunakan diagram triangular, dimana untuk bagian yang telah diarsir berwarna oranye merupakan bagian 1 fasa dan untuk bagian yang diarsir berwarna biru bagian adalah 2 fasa seperti yang ditunjukkan pada gambar 2 .

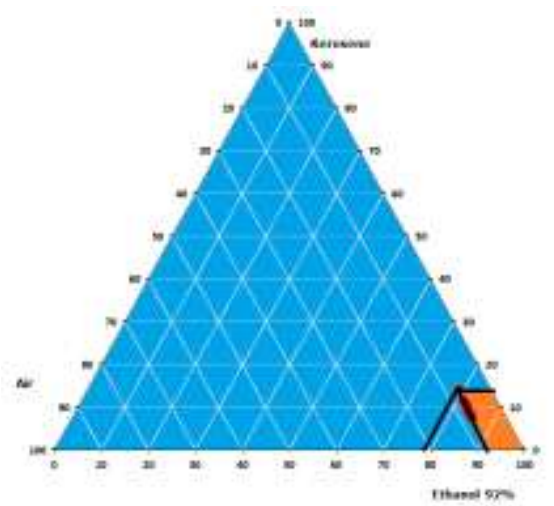

Gambar 2. Diagram triangular antara ethanol 92\%-kerosene-air.

\section{KESIMPULAN}

Pencampuran antara etanol, kerosene, dan air dapat dilakukan dengan melalui proses cracking terlebih dahulu. Pencampuran etanol $98 \%$ dengan kerosene dan air hanya membutuhkan volume etanol yang sedikit. Sedangkan untuk pencampurkan etanol $92 \%$ dengan kerosene dan air membutuhkan volume etanol yang banyak. Pencampuran etanol, air dan suhu terendah dari hasil cracking kerosene semakin baik untuk menjadi emulsi satu fasa, karena tidak membutuhkan etanol yang banyak dan lebih mudah tercampur. Etanol dari nira aren dapat menjadi bahan bakar emulsi satu fasa. Bahan bakar emulsi adalah pencampuran antara etanol hasil destilasi refluks dan kerosene hasil cracking.

\section{SARAN}

Penelitian ini perlu dikembangkan untuk bahan bakar yang lebih ramah lingkungan.

\section{DAFTAR PUSTAKA}

Bambang. 2006. Biodiesel Sumber Energi Alternatif Pengganti Solar Yang Terbuat Dari Ekstraksi Minyak Jarak Pagar. Surabaya: Trubus Agrisarana.

Demirbas A. 2006. Hazardous emissions, global climate change and environmental precautions. Energy Sources. 1:75-84.

Garai A., S Pal., S Mondal., S Ghosh., S Sen., A Mukhopadhyay. 2017. Experimental investigation of spray characteristics of kerosene and ethanol-blended kerosene using a gas turbine hybrid atomizer. Indian Academy of Science. 42(4):543555.

Khalil A., A Gupta. 2012. Fuel flexible distributed combustion for gas turbine engines. American Institute of Aeronautics and Astronautics. DETC201270246.

Najafi G., B Ghobadian., T Yusaf., SMS Ardebili., R Mamat. 2015. Optimization of performance and exhaust emission parameters of a SI (spark 
ignition) engine with gasolineeethanol blended fuels using response surface methodology. Energy. 90 : 115.

Patra J., P Ghose., A Datta., M Das., R Ganguly., S Sen., S Chatterjee. 2015. Studies of combustion characteristics of kerosene ethanol blends in an axisymmetric combustor. Fuel. 144: 205-213.

Patil KR., SS Thipse. 2015. Experimental investigation of CI engine combustion, performance and emissions in DEE-kerosenediesel blends of high DEE concentration. Energy Conversion and Management. 89: 396-408.

Rakopoulus DC., CD Rakopoulus., EG Giakoumis., AM Dimartos., DC Kyritsis. 2010. Effects of butanol-diesel fuel blends on the performance and emissions of a high-speed DI diesel engine. Energy Conversion and Management. 51: 1989-1997.

Sangian HF., GH Tamuntuan., HIR Mosey., VA Suoth., BH Manialup. 2017. The utilization of arenga pinnata ethanol in preparing one phase-aqueous gasohol. ARPN Journal of Engineering and Applied Sciences. 12(24):7039-7046.

Sangian HF., J Kristian., S Rahma., HK Dewi., DA Puspasari., SY Agnesty., S Gunawan., A Widjaja. 2015. Preparation of reducing sugar hydrolyzed from high-lignin coconut coir dust pretreated by the recycled ionic liquid [mmim][dmp] and combination with alkaline. Bulletin of Chemical Reaction Engineering \& Catalysis. 10(1): 8-22.
Sangian HF., JR Pangau., GH Tamuntuan., Z Zulnazri. 2018. The Structural Analysis of the Lignocellulose, Champaca Timber (Elmerrilliaovalis) Modified by the Microwave. Chemical Engineering Transactions. 65: 229-234.

Sangian HF., A Widjaja. 2019. Mathematical model of enzymatic reactions of coconut coir substrate treated by alkaline and ionic liquid into the reducing sugars using power series. IOP Conference Series: Materials Science and Engineering. 567(1): 012006.

Wildenborg $\mathrm{T}$ and Lokhorst A. 2005. Introduction on $\mathrm{CO} 2$ geological storage-classification of storage options. Oil Gas Sci Technol Rev IFP. 60:513-5

Widjaja A., SY Agnesty., HF Sangian., S Gunawan. 2015. Application of Ionic Liquid [DMIM]DMP Pretreatment in the Hydrolysis of Sugarcane Bagasse for Biofuel Production. Bulletin of Chemical Reaction Engineering \& Catalysis. 10(1):70-77.

Yilmaz N., MF Vigil., BA Donaldson., T Darabseh. 2013. Investigation of $\mathrm{CI}$ engine emissions in biodiesel-ethanol-diesel blends as a function of ethanol concentration. Fuel. 115 : 1-4. 